\title{
Gynecologic Conditions and Bacterial Vaginosis: Implications for the Non-Pregnant Patient
}

\author{
Richard L. Sweet \\ Department of $O B / G Y N / R S$, Magee-Womens Hospital, Pittsburgh, PA
}

\begin{abstract}
Bacterial vaginosis is characterized by a shift from the predominant lactobacillus vaginal flora to an overgrowth of anaerobic bacteria. Bacterial vaginosis is associated with an increased risk of gynecologic complications, including pelvic inflammatory disease, postoperative infection, cervicitis, human immunodeficiency virus (HIV), and possibly cervical intraepithelial neoplasia (CIN). The obstetrical risks associated with bacterial vaginosis include premature rupture of membranes, preterm labor and delivery, chorioamnionitis and postpartum endometritis. Despite the health risks associated with bacterial vaginosis and its high prevalence in women of childbearing age, bacterial vaginosis continues to be largely ignored by clinicians, particularly in asymptomatic women. Infect. Dis. Obstet. Gynecol. 8:184-190, 2000. ๑ 2000 Wiley-Liss, Inc.
\end{abstract}

KEY WORDS

vaginal flora; Gardnerella vaginalis; pelvic inflammatory disease; endometritis; cervical intraepithelial neoplasia

$B^{a}$ acterial vaginosis (BV) is the most common vaginal infection among women of childbearing age. ${ }^{1-4} \mathrm{BV}$ occurs in $33 \%$ to $36 \%$ of women attending sexually transmitted disease clinics, $16 \%$ to $20 \%$ of pregnant women, and in up to $25 \%$ of women attending gynecologic clinics. ${ }^{5-9}$ Thus, routine screening and prompt treatment of $\mathrm{BV}$ in these populations may be critical in certain clinical scenarios.

$\mathrm{BV}$ is characterized by a disruption in the vaginal flora whereby anaerobic bacteria, Mycoplasma hominis and Gardnerella vaginalis overgrow at the expense of protective lactobacilli. Although the exact cause of bacterial vaginosis is unknown, predisposing factors include douching, previous sexually transmitted disease, a change in sexual partner, and use of intrauterine devices. ${ }^{9-11}$ High prevalence rates have been reported in patients attending sexually transmitted disease clinics, yet $\mathrm{BV}$ has been noted in virginal women as well. ${ }^{11,12}$

The most common outward symptoms of BV include a thin, homogeneous, milky white or dull gray vaginal discharge, a foul or fishy odor that may intensify following sexual intercourse, and sometimes vaginal burning or itching. However, as many as $50 \%$ of all women with $\mathrm{BV}$ are asymptomatic. ${ }^{13}$ Therefore, it is critical that patients are educated about BV and routinely screened for this infection. Clinically, bacterial vaginosis is diagnosed by the presence of three of the following four criteria: a vaginal $\mathrm{pH}$ of greater than 4.5 , the presence of clue cells in the vaginal fluid, a thin, white or gray homogeneous vaginal discharge, or a positive $\mathrm{KOH}$ whiff test-the release of an amine (fishy) odor upon the addition of $10 \%$ potassium hydroxide to the vaginal fluid. ${ }^{13}$ Use of Gram stain is an alternative using the Nugent criteria for the diagnosis of

Grant sponsor: 3M Pharmaceuticals

*Correspondence to: Richard L. Sweet, M.D., Magee-Womens Hospital, Department of OB/GYN/RS, 300 Halket Street, Pittsburgh, PA 15213-3180. E-mail: rsweet@mail.magee.edu 
BV. ${ }^{14}$ It has been shown to correlate well with clinical criteria and is an effective way to screen for asymptomatic BV. However, because Gram stain can be logistically more difficult due to the need for laboratory evaluation, the majority of practitioners use wet mount to detect the presence of clue cells, pH tests, and "whiff" tests.

While BV was once thought to be merely a nuisance condition, more recent investigations have demonstrated that it is associated with an increased risk of gynecologic and obstetric complications. Gynecologic conditions associated with BV include pelvic inflammatory disease, ${ }^{15,16}$ postoperative infection such as postabortion endometritis ${ }^{17,18}$ and pelvic cuff cellulitis following hysterectomy, ${ }^{19,20}$ cervicitis, ${ }^{21}$ human immunodeficiency virus (HIV), 22-24 and possibly cervical intraepithelial neoplasia (CIN). ${ }^{25}$ The obstetrical risks associated with BV include premature rupture of membranes, preterm labor and delivery, ${ }^{7}$ chorioamnionitis, ${ }^{26}$ and postpartum endometritis. ${ }^{26}$

Despite its prevalence and associated health risks, bacterial vaginosis remains underdiagnosed by clinicians and poorly understood by patients. Research by Wiesenfeld and Macio ${ }^{27}$ found that three of the four standard diagnostic procedures for bacterial vaginosis were not routinely performed to evaluate women with vulvovaginal symptoms. Of 150 office visits with 50 different physicians, $58 \%$ routinely performed microscopy, while $\mathrm{pH}$ and whiff tests were performed by only $2 \%$ and $8 \%$ of physicians, respectively.

Low patient awareness of $\mathrm{BV}$ is suggested by two recent surveys. In a 1993 Gallup survey of 1,011 women aged 18 years or older, $64 \%$ of respondents reported that they had never heard of bacterial vaginosis. ${ }^{28}$ Similarly, a 1998 survey of 301 women aged 18-50 who reported having at least one vaginal infection in the previous three years, determined that $80 \%$ of the respondents could not identify the symptoms of bacterial vaginosis. ${ }^{29}$

Given the health risks associated with bacterial vaginosis, low patient awareness combined with poor diagnostic practice may have significant implications for the female patient. While much of the recent literature has focused on obstetrical complications, greater emphasis should be placed on the non-pregnant patient for whom gynecologic health risks pose the greatest threat. Indeed, bacterial vaginosis is believed to be the cause of one- third to one-half of all infectious vaginal conditions. ${ }^{5}$ Moreover, because non-pregnant women represent the majority of $\mathrm{BV}$ cases, many of whom may be asymptomatic, routine screening and prompt treatment in this population is critical. This article will discuss the pathogenesis of $\mathrm{BV}$ and review the literature documenting the link between $\mathrm{BV}$ and several of the most common gynecologic conditions.

\section{ETIOLOGY OF BV: A NATURAL LINK TO GENITAL TRACT COMPLICATIONS}

Though the etiology of bacterial vaginosis is not completely understood, research has confirmed that $\mathrm{BV}$ is a synergistic, polymicrobial infection characterized by a shift in the bacterial flora of the vagina. Normal vaginal flora consists predominantly of lactobacilli, though both aerobic and anaerobic bacteria also can be found in small numbers. Lactobacilli serve as a natural host defense by producing both lactic acid, which maintains the vaginal $\mathrm{pH}$ below 4.5, and hydrogen peroxide, which inhibits the growth of non-catalaseproducing microorganisms. ${ }^{26}$ This combination creates a potent defense against the overgrowth of other vaginal bacteria, particularly anaerobes. ${ }^{26}$

In women with $\mathrm{BV}$, the concentration of lactobacilli is significantly reduced (fewer than 10,000 colonies/ml of vaginal fluid) allowing for the overgrowth of anaerobes, Gardnerella vaginalis and $M y$ coplasma hominis, which prevail in numbers 100 to 1000 times higher than in women with normal flora. ${ }^{26}$ In particular, G. vaginalis, Peptostreptococcus spp., Prevotella spp., and Mobiluncus spp. are present in increased numbers in women with $\mathrm{BV}$.

Due to the proximity and permeability of the lower and upper genital tract mucosa, a dominance of pathogens in the vagina places women with $\mathrm{BV}$ at higher risk for upper genital tract infection. ${ }^{26}$ In addition, enzymes and metabolic byproducts of abnormal vaginal flora impede normal white blood cell response to infection. ${ }^{12}$ Specifically, BV has been implicated in the gynecologic conditions discussed below.

\section{POSTOPERATIVE INFECTION}

Postoperative infection continues to be a common complication of gynecologic surgery. Specifically, pelvic inflammatory disease (PID) following firsttrimester abortion and pelvic cellulitis following 
abdominal hysterectomy are particularly prevalent. The incidence of PID following first-trimester abortion is $4 \%$ to $12 \%$ and postoperative pelvic cellulitis occurs in up to $70 \%$ of patients undergoing hysterectomy without prophylaxis. ${ }^{18,30}$ Research has identified bacterial vaginosis as a risk factor for development of both of these conditions.

\section{Postabortion Endometritis/PID}

The presence of Mobiluncus and clue cells in vaginal smears has been clinically correlated with bacterial vaginosis. In a study by Larsson et al., ${ }^{17}$ women in whom Mobiluncus and clue cells were detected were found to have a higher risk of postabortion pelvic inflammatory disease than women without presence of these organisms. Women in this study also were examined for $C$. trachomatis, which previously has been identified as a risk factor for PID.

Mobiluncus were identified in specimens from 81 women (15.2\%), while $C$. trachomatis presented in specimens from 39 women (7.6\%). A combination of Mobiluncus and C. trachomatis was detected in 11 cases. In women where Mobiluncus had been seen, the incidence of PID was $10.8 \%$, compared with $4.5 \%$ of women with neither Mobiluncus nor C. trachomatis.

Additionally, clue cells were detected in 65 of the $198(32.8 \%)$ Gram-stained smears, while 133 $(67.2 \%)$ indicated normal epithelium cells. The incidences of PID in these groups were $11.8 \%$ and $3.2 \%$ respectively $(P=0.01)$. Moreover, women identified with $C$. trachomatis were younger than the rest of the study population, indicating two possible risk groups for developing PID after firsttrimester abortion.

Further research by Larsson et al. ${ }^{18}$ confirms an association between BV and postabortion pelvic inflammatory disease, and underscores the benefits of prophylactic therapy. In a double-blind, randomized placebo-controlled study of 231 women undergoing first-trimester abortion and fulfilling the criteria for $\mathrm{BV}$, subjects were randomized to receive either $500 \mathrm{mg}$ of metronidazole three times daily or placebo for ten days. Women with $G$. trachomatis infection were excluded from the study group. Among the 174 women who could be evaluated, pelvic inflammatory disease developed in three women in the treatment group $(3.6 \%)$ compared to $11(12.2 \%)$ in the placebo group $(P<0.05)$. Thus, treatment with metronidazole in women with bacterial vaginosis undergoing first-trimester abortion resulted in a threefold reduction in the rate of postoperative pelvic inflammatory disease.

Postabortion pelvic inflammatory disease was defined as two or more of the following six criteria fulfilled within 28 days of the surgery: (1) abnormal or purulent vaginal discharge after 1 week, (2) abnormal bleeding after the third day, (3) temperature $>38.0^{\circ} \mathrm{C}\left(100.4^{\circ} \mathrm{F}\right)$ for $>24$ hours, (4) palpable adnexal masses, (5) tenderness over the uterus or adnexa on pelvic examination, or (6) erythrocyte sedimentation rate $>30 \mathrm{~mm}$.

\section{Posthysterectomy Infection/Pelvic Cuff Cellulitis/Postcesarean Endometritis}

A study by Soper et al. ${ }^{19}$ found that women with bacterial vaginosis had a three times higher risk of developing cuff cellulitis, cuff abscess, or both following abdominal hysterectomy than women without BV (relative risk 3.2, 95\% confidence interval 1.5 to 6.7). Moreover, organisms associated with BV including G. vaginalis, Bacteroides spp., or Peptostreptococcus spp. were isolated from the vaginal cuff of more than $60 \%$ of cases of cuff cellulitis. ${ }^{19}$ Cuff cellulitis was defined by persistent fever on two occasions, excluding the first 48 hours postsurgery, in association with increased vaginal cuff tenderness and induration on bimanual pelvic examination. Cuff abscess was diagnosed in patients meeting the criteria for cuff cellulitis, who also had a palpable, fluctuant mass located superior to the vagina.

These findings were confirmed by Larsson et al. In their study of 70 women scheduled for abdominal hysterectomy, 7 of 20 women $(35 \%)$ with BV, as identified by the presence of clue cells in the vaginal discharge, developed vaginal cuff infections, versus 4 of 50 women (8\%) without clue cells. ${ }^{20}$ Vaginal cuff infections were defined by the presence of at least two of the following: temperature higher than $38^{\circ} \mathrm{C}$ after the third postoperative day, foul-smelling discharge, or increasing abdominal pain after the second postoperative day. Importantly, none of the patients in this study or in the aforementioned Soper study received antibiotic prophylaxis.

More recently, Lin et al. ${ }^{31}$ conducted a prospective study, which looked at both intermediate and definite stages of $\mathrm{BV}$ as potential risk factors for 
postoperative infection following gynecologic surgery. In this study, 175 women undergoing major gynecologic surgery, which included benign gynecologic, urogynecologic, and gynecologic oncology cases, were evaluated for the presence of BV based on Nugent's criteria. The criterion for positive-BV was a score of 7 or higher, while intermediate BV was defined by a score of 4 to 6. Lactobacilluspredominant flora was defined by a score of 0 to 3 . Thirty-six percent of the positive-BV group developed a postoperative fever, compared with $20 \%$ of the Lactobacillus-predominant group and $12 \%$ of the intermediate-BV group $(P=0.017)$. The difference between the positive-BV group and the intermediate-BV group was statistically significant $(P=$ 0.045 and $P=0.007$, respectively), while the difference between the intermediate-BV group and the Lactobacillus-predominant group was not.

Research identifying bacterial vaginosis as a risk factor for postcesarean endometritis was conducted by Watts et al. ${ }^{32}$ in 1990 and by Sanchez-Ramos et al. ${ }^{33}$ in 1999 . Watts et al. found that women with bacterial vaginosis, as diagnosed by Gram stain, were approximately six times more likely to develop postcesarean endometritis than women with normal vaginal flora. ${ }^{32}$ Postpartum endometritis was diagnosed in $34(35 \%)$ of the 97 patients with bacterial vaginosis compared with $35(10 \%)$ of the 365 women with normal flora $(P<0.001)$, despite the use of antibiotic prophylaxis. ${ }^{32}$

In an additional study presented at the Society of Maternal Fetal Medicine in early 1999, SanchezRamos et al. ${ }^{33}$ looked at treating pregnant women, at least 24-weeks gestation, prior to cesarean section with topical metronidazole or placebo. An interim analysis of this double-blinded trial showed that $6 \%$ of women treated with topical metronidazole developed postcesarean endometritis versus $28 \%$ of patients who received placebo gel $(P=$ $0.04)$. The authors also noted that patients receiving placebo required a more prolonged postpartum stay. $^{33}$

Based on the significant body of evidence linking $\mathrm{BV}$ with postsurgical infection, preoperative screening for and treatment of $\mathrm{BV}$ is recommended.

\section{PELVIC INFLAMMATORY DISEASE}

Pelvic inflammatory disease, which refers to inflammation of the upper genital tract, includes any one or a combination of the following conditions: endometritis, salpingitis, pelvic peritonitis, or tuboovarian abscess. Though the exact etiology of PID is not completely understood, it is believed to occur by the ascension of microorganisms from the vagina or endocervix to the endometrium and fallopian tubes. ${ }^{34} \mathrm{~A}$ significant body of research demonstrates that the presence of bacterial vaginosisassociated organisms is strongly associated with the development of pelvic inflammatory disease.

Soper et al. found that bacterial vaginosis was present in $62 \%$ of patients with confirmed acute salpingitis $(n=84) .{ }^{16}$ Moreover, $100 \%$ of the anaerobes isolated from the upper genital tract of these women were microorganisms found in bacterial vaginosis.

Findings by Hillier et al. support these results. ${ }^{34}$ They found that high concentrations of pathogenic microorganisms, most frequently those associated with bacterial vaginosis including $G$. vaginalis, anaerobic Gram-negative rods, Peptostreptococcus spp., and $M$. hominis, were recovered from the endometria of $94 \%$ of women with histologic endometritis ( $n=117)$. Similarly, bacterial vaginosis-associated organisms were detected in the fallopian tubes or peritoneal fluid of more than half $(55 \%)$ of the patients. Furthermore, Hillier et al. clearly demonstrated that presence of BV-associated organisms is associated with plasma cell endometritis even after controlling for Chlamydia and Neisseria gonorrhoeae.

In a study by Korn et al., ${ }^{35}$ plasma cell endometritis was frequently observed in women with bacterial vaginosis. Plasma cell endometritis was noted in 10 of the 22 patients (45\%) with $\mathrm{BV}$, versus 1 of $19(5 \%)$ women in the control group $(P<0.01)$. Furthermore, bacterial vaginosis-associated organisms were elicited from the endometria of 9 of 11 women with plasma cell endometritis and 8 of the 30 women without plasma cell endometritis $(P=$ $0.002)$.

Recent research by Peipert et al. further documents the association between BV and upper genital tract infection. ${ }^{36}$ In their study of 116 women meeting the minimal criteria of the Centers for Disease Control and Prevention for acute pelvic inflammatory disease or with other "nonclassic" signs of upper genital tract infection (e.g., atypical pelvic pain or abnormal uterine bleeding), object evidence of upper genital tract infection was present in $56 \%(14 / 25)$ of women with the clinical 
diagnosis of bacterial vaginosis compared with $30 \%$ of women (27/91) who did not meet the clinical criteria. The presence of BV was associated with a threefold increased risk of upper genital tract infection. The objective criteria used for diagnosis of upper genital tract infection included histologic endometritis or salpingitis, laparoscopic evidence of salpingitis, or microbiologic evidence of $N$. gonorrhea or $C$. trachomatis from the endometrium or fallopian tubes.

\section{CERVICITIS}

It is estimated that as many as one-half of women attending sexually transmitted disease (STD) clinics with clinically defined cervicitis have coexisting $\mathrm{BV}{ }^{21} \mathrm{~A}$ direct link between the two disease states is demonstrated in findings by Schwebke et al. who reported that cervicitis did not respond to recommended treatment unless coexisting BV was treated. ${ }^{21}$ In their pilot study of women with coexistent $\mathrm{BV}$ and cervicitis attending an STD clinic, patients were treated in two phases. During phase I, women were treated with doxycycline alone; in phase II, patients were treated with both doxycycline and intravaginal metronidazole gel. Results showed $86 \%$ of women who were treated concomitantly with doxycycline and metronidazole gel had clinical resolution of their cervicitis, compared with $53 \%$ of women who did not receive the intravaginal metronidazole. ${ }^{21}$

\section{HUMAN IMMUNODEFICIENCY VIRUS}

As the proportion of women acquiring HIV through heterosexual transmission continues to increase, emerging research demonstrates an association between abnormal vaginal flora and increased susceptibility to HIV. Data from several large-scale studies suggests a potential role for $\mathrm{BV}$ in $\mathrm{HIV}$ transmission.

One of the first clinical studies to demonstrate the association between bacterial vaginosis and HIV was conducted by Cohen et al. ${ }^{24}$ This crosssectional study of 144 commercial sex workers in Thailand reported a clinical diagnosis of BV in $47 \%$ of the HIV-positive women compared with $24 \%$ of the HIV-negative women-a fourfold increase in the risk of $\mathrm{BV}$ in the HIV group after accounting for other variables.

In a prevalence study of 4,718 pregnant women in rural Uganda, $27 \%$ of women with severe bacte- rial vaginosis had HIV, whereas $14 \%$ of women with normal vaginal flora had $\operatorname{HIV}(P<0.0001)$. Women with HIV had a $50 \%$ increased prevalence of moderate BV (Gram stain score 7 to 8 ) and a $110 \%$ increased prevalence of more severe BV (Gram stain score 9 to 10) after controlling for selected other infections. ${ }^{22}$

A 1998 trial of 1,196 pregnant women in Malawi demonstrated for the first time that a woman's risk of acquiring HIV increased in direct proportion to the severity of bacterial disturbances in the vagina. Women with severe bacterial vaginosis were 3.7 times more likely to acquire HIV than women without BV. ${ }^{23}$

Most recently, a 1999 study by Taha et al. provides further support for an association between bacterial vaginosis and prevalence of HIV infection. ${ }^{37}$ In two cross-sectional studies conducted among pregnant women in urban Malawi the prevalence of HIV-1 was $23 \%$ and $30 \%$ in 1990 and 1993, respectively. Overall, $30 \%$ of women with HIV also presented with BV, as diagnosed by Amsel's criteria. Furthermore, 59\% had mild or moderate disturbances in vaginal flora (indicated by the presence of one and two of Amsel's criteria, respectively), while only $11 \%$ had normal flora.

\section{CERVICAL INTRAEPITHELIAL NEOPLASIA}

Cervical intraepithelial neoplasia and cervical cancer are major causes of morbidity and mortality among women. It has been suggested that bacterial vaginosis could be important in the development of CIN.

Scandinavian studies have shown good correlation between clue cells on Pap and BV. Davis et al. recently reported that Pap smear had a specificity of $98 \%$ and a positive predictive value of $96 \%$ in the diagnosis of BV versus Gram stain. ${ }^{38}$

In a study by Platz-Christensen et al. ${ }^{25}$ to investigate the association between the presence of clue cells in PAP smears and CIN, GIN occurred in 5\% of women with $\mathrm{BV}$ versus $1.4 \%$ of women without $\mathrm{BV}$. The relative risk for having any CIN was 8.0 if bacterial vaginosis was present (95\% confidence interval 4.1-15.6) and the relative risk for having CIN III/CIS was 5.0 if BV was also present. ${ }^{25}$

Findings by Eltabbakh et al. further support an association between bacterial vaginosis and abnormal cytology. ${ }^{39}$ Their research found that $50 \%$ of 963 asymptomatic women presenting for an annual 
Pap smear also had a vaginal and/or cervical infection, the most prevalent of which was bacterial vaginosis, which presented in $28 \%$ of patients. Furthermore, a diagnosis of $\mathrm{BV}$ on wet mounts was associated with inflammation and atypical cells in Pap smears in $50 \%$ of cases.

Further studies are required to verify if an association between BV and CIN exists. Whether BV is related to development of CIN as a cofactor with human papillomavirus or produces inflammation obscuring accurate Pap smear interpretation is yet unclear.

\section{CONCLUSION}

A substantial body of research has confirmed the association between bacterial vaginosis and various gynecologic conditions, some of which have potentially serious implications for the non-pregnant patient. Currently, treatment is the only method clinicians have to positively effect the vaginal flora. The recommended treatments consist of both topical and oral metronidazole or clindamycin. They all have been shown to be equally efficacious at treating $\mathrm{BV}$, although there are differences in systemic absorption, side effects, convenience, and patient acceptance. Given the potential for bacterial vaginosis to greatly impact a woman's reproductive and overall health, clinicians should place greater emphasis on maintaining a healthy vaginal flora in their gynecologic patients. This may be accomplished through more frequent screening for and prompt treatment of bacterial vaginosis.

\section{REFERENCES}

1. Mallon M. Vaginal infections. PA Today. Sept. 29, 1997. p. 13-17.

2. Lash DJ, Garcia TA. Diagnosis and treatment of vaginitis. The Female Patient 1998;23:73-93.

3. Smith RP. 1997. Assessing and managing vaginitis. IM Intern Med 1997;18:31-42.

4. Holst E, Wathne B, Hovelius B, Mårdh P-A. Bacterial vaginosis: microbiological and clinical findings. Eur $\mathrm{J}$ Clin Microbiol 1987;6:536-541.

5. Eschenbach DA, Hillier S, Critchlow G, et al. Diagnosis and clinical manifestations of bacterial vaginosis. Am J Obstet Gynecol 1988;158:819-828.

6. Hallén A, Påhlson C, Forsum U. Bacterial vaginosis in women attending STD clinic: diagnostic criteria and prevalence of Mobiluncus spp. Genitourin Med 1987;63: 386-389.

7. Hillier SL, Nugent RP, Eschenbach DA, et al. for the
Vaginal Infections and Prematurity Study Group. Association between bacterial vaginosis and preterm delivery of a low-birth-weight infant. N Engl J Med 1995;333: $1737-1742$.

8. Martius J, Krohn MA, Hillier SL, et al. Relationships of vaginal Lactobacillus species, cervical Chlamydia trachomatis, and bacterial vaginosis to preterm birth. Obstet Gynecol 1988;71:89-95.

9. Amsel R, Totten PA, Spiegel CA, et al. Nonspecific vaginitis: diagnostic criteria and microbial and epidemiologic associations. Am J Med 1983;74:14-22.

10. Taylor-Robinson D, Hay PE. The pathogenesis of the clinical signs of bacterial vaginosis and possible reasons for its occurrence. Int J STD AIDS 1997;8(suppl 1):1316.

11. Biswas MK. Bacterial vaginosis. Clin Obstet Gynecol 1993;36:166-176.

12. Thomason JL, Gelbart SM, Scaglione NJ. Bacterial vaginosis: current review with indications for asymptomatic therapy. Am J Obstet Gynecol 1991;165:1210-1217.

13. Miller KE, Worthington JM. Evaluation and treatment of bacterial vaginosis: an update. Fam Pract Recertification 1997;19:33-52.

14. Nugent RP, Krohn MA, Hillier SL. Reliability of diagnosing bacterial vaginosis is improved by a standardized method of gram stain interpretation. J Clin Microbiol 1991;29:297-301.

15. Paavonen J, Teisala K, Heinonen PK, et al. Microbiological and histopathological findings in acute pelvic inflammatory disease. Br J Obstet Gynaecol 1987;94:454460.

16. Soper DE, Brockwell NJ, Dalton HP, Johnson D. Observations concerning the microbial etiology of acute salpingitis. Am J Obstet Gynecol. 1994;170:10081014.

17. Larsson P-G, Bergman B, Forsum U, Platz-Christensen $\mathrm{J}-\mathrm{J}$, Pahlson C. Mobiluncus and clue cells as predictors of PID after first-trimester abortion. Acta Obstet Gynecol Scand 1989;68:217-220.

18. Larsson P-G, Platz-Christensen J-J, Theijls H, Forsum $\mathrm{U}, \mathrm{Pahlson} \mathrm{C}$. Incidence of pelvic inflammatory disease after first-trimester legal abortion in women with bacterial vaginosis after treatment with metronidazole: A double-blind, randomized study. Am J Obstet Gynecol 1992;166:100-103.

19. Soper DE, Bump RC, Hurt WG. Bacterial vaginosis and trichomoniasis vaginitis are risk factors for cuff cellulitis after abdominal hysterectomy. Am J Obstet Gynecol 1990;163:101-123.

20. Larsson P-G, Platz-Christensen J-J, Forsum U, Pahlson C. Clue cells in predicting infections after abdominal hysterectomy. Obstet Gynecol 1991;77:450.

21. Schwebke JR, Schulien MB, Zajackowski M. Pilot study to evaluate the appropriate management of patients with coexistent bacterial vaginosis and cervicitis. Infect Dis Obstet Gynecol 1995;3:119-122.

22. Sewankambo N, Gray R, Wawer MJ, et al. HIV-1 infection associated with abnormal vaginal flora morphology and bacterial vaginosis. Lancet 1997;350:546-550. 
23. Taha TE, Hoover DR, Dallabetta GA, et al. Bacterial vaginosis and disturbances of vaginal flora: association with increased acquisition of HIV. AIDS 1998;12:16991706.

24. Cohen CR, Duerr A, Pruithithada N, et al. Bacterial vaginosis and HIV seroprevalence among female commercial sex workers in Chiang Mai, Thailand. AIDS. 1995;9:1093-1097.

25. Platz-Christensen JJ, Sundstrom E, Larsson PG. Bacterial vaginosis and cervical intraepithelial neoplasia. Acta Obstet Gynecol Scand 1994;73:586-588.

26. Eschenbach DA. Bacterial vaginosis and anaerobes in obstetric-gynecologic infection. Clin Infect Dis 1993;16(suppl 4):S282-S287.

27. Wiesenfeld HC, Macio I. Evaluation of vulvovaginal symptoms by women's health care providers. Infect Dis Obstet Gynecol 1998;6:103-104.

28. The Gallup Organization. Women's awareness and knowledge of vaginal infections. November 1993; 424044.

29. 3M National Vaginitis Association and the American Social Health Association. Survey of women's knowledge of vaginal infections. April 1998.

30. Soper DE. Bacterial vaginosis and postoperative infections. Am J Obstet Gynecol 1993;169:467-469.

31. Lin L, Song J, Kimber N, et al. The role of bacterial vaginosis in infection after major gynecologic surgery. Infect Dis Obstet Gynecol 1999;7:169-174.

32. Watts DH, Krohn MA, Hillier SL, Eschenbach DA.
Bacterial vaginosis as a risk factor for post-cesarean endometritis. Obstet Gynecol 1990;75:52.

33. Sanchez-Ramos L, Pitt C, Delke I, Gaudier FL. Preoperative administration of intravaginal metronidazole for the prevention of post-cesarean endometritis: A randomized double-blind trial. Am J Obstet Genecol 1999;180(1 pt 2):S81.

34. Hillier SL, Kiviat NB, Hawes SE, et al. Role of bacterial vaginosis-associated microorganisms in endometritis. Am J Obstet Gynecol 1996;175:435-441.

35. Korn AP, Bolan G, Padian N, et al. Plasma cell endometritis in women with symptomatic bacterial vaginosis. Obstet Gynecol 1995;85:387-390.

36. Peipert JF, Montagno AB, Cooper AS, Sung CJ. Bacterial vaginosis as a risk factor for upper genital tract infection. Am J Obstet Gynecol 1997;177:1184-1187.

37. Taha TE, Gray RH, Kumwenda NI, et al. HIV infection and disturbances of vaginal flora during pregnancy. J Acquir Immune Defic Syndr Hum Retrovirol 1999;20: 52-59.

38. Davis JD, Connor EE, Clark P, Wilkinson EJ, Duff P. Correlation between cervical cytologic results and Gram stain as diagnostic tests for bacterial vaginosis. Am J Obstet Gynecol 1997;177:532-535.

39. Eltabbakh GH, Eltabbakh GD, Broekhuizen FF, Griner BT. Value of wet mount and cervical cultures at the time of cervical cytology in asymptomatic women. Obstet Gynecol 1995;85:499-503. 